\title{
ANALISIS DAYA DUKUNG PULAU LIUKANG LOE UNTUK PENGEMBANGAN WISATA PANTAI
}

\author{
Muhammad Arhan Rajab \\ Jurusan Manajemen Pariwisata, STIPAR Tamalatea, Makassar \\ Sekolah Tinggi Pariwisata Tamalatea; Jl. Perintis Kemerdekaan Km. 12 Makassar \\ E-mail Korespondensi: arhanrajab@stipartamalatea.ac.id
}

\begin{abstract}
ABSTRAK
Pulau Liukang Loe terletak di Kabupaten Bulukumba Sulawesi Selatan. Wilayah ini memiliki daya tarik berupa pantai berpasir putih dan landai serta pemandangan laut yang indah. Penelitian ini dilaksanakan dengan tujuan untuk mengkaji kesesuaian lahan dan daya dukung (carrying capacity) Pulau Liukang Loe untuk kegiatan wisata pantai. Penelitian ini dilaksanakan pada Bulan Maret 2020. Penelitian ini menggunakan metode survey dengan menggunakan ground check dan pengukuran parameter in situ serta studi literatur dari berbagai sumber data sekunder. Berdasarkan hasil penelitian menunjukkan bahwa potensi wisata pantai termasuk dalam kategori sesuai dengan panjang pantai $1.411 \mathrm{~m}$ dan sesuai bersyarat dengan panjang pantai $1.279 \mathrm{~m}$. Kategori sesuai berada di pantai sebelah utara (Kampung Ta'buntuleng) dan kategori sesuai bersyarat berada di pantai sebelah tenggara (Kampung Pasilohe) dengan daya dukung kawasan kategori wisata pantai sebesar 56 (Orang/hari).
\end{abstract}

Kata Kunci: wisata pantai, kesesuaian lahan, daya dukung, pulau liukang loe.

\begin{abstract}
Liukang Loe Island is located in Bulukumba Regency, South Sulawesi. This region has the attraction of white sandy beaches and gently sloping and beautiful sea views. This research was conducted with the aim to examine the suitability of land and carrying capacity (carrying capacity) of Liukang Loe Island for beach tourism activities. This research was conducted in March 2020. This study used a survey method using ground check and measurement of parameters in situ as well as literature studies from various secondary data sources. Based on the results of the study showed that the potential for beach tourism included in the category according to the length of the beach 1,411 $\mathrm{m}$ and according to conditional with the length of the beach 1,279 $\mathrm{m}$. The appropriate category is located on the north coast (Ta'buntuleng Village) and the conditional appropriate category is on the southeast coast (Pasilohe Village) with the carrying capacity of the coastal tourism category at 56 (person / day).
\end{abstract}

Keywords: beach tourism, land suitability, carrying capacity, liukang loe island 


\section{PENDAHULUAN}

Pulau-pulau kecil memiliki potensi sumberdaya yang sangat besar ditandai dengan adanya keanekaragaman ekosistem seperti pada ekosistem mangrove, lamun dan terumbu karang beserta biota yang hidup di sekitar wilayah pulau-pulau kecil. Keberadaan potensi tersebut dapat dimanfaatkan untuk peningkatan produksi perikanan, ekowisata bahari, konservasi dan jenis pemanfaatan lainnya. Wilayah pesisir dan laut yang dapat dikembangkan menjadi kawasan wisata berupa pemandangan pantai yang indah dan keaslian lingkungan seperti kehidupan di bawah air. Pengembangan pantai sebagai tempat ekowisata merupakan jasa lingkungan dari alokasi sumberdaya yang cenderung akan memberikan manfaat pada kepuasan batin seseorang dikarenakan mengandung nilai estetika tertentu (Ali 2004).

Pengembangan kawasan pulau-pulau kecil sebagai lokasi ekowisata bahari memerlukan koordinasi dan integrasi dari beberapa unsur dengan mengacu pada kondisi internal lokasi yang menyangkut aspek ekologi, kesesuaian, daya dukung dan sosial budaya masyarakat. Oleh karena itu perlu dirancang desain pengelolaan yang terpadu. Selain itu juga pulau-pulau kecil sangat rentan karena sifatnya yang khas akibat kecilnya ukuran dibanding daratan (smallness) serta terisolasi dari pulau besar/induk (remotness) serta akibat tekanan dari aktivitas manusia yang sifatnya destruktif (Dahuri, 2003; Bengen, 2003).

Pulau Liukang Loe merupakan pulau yang terletak di Kabupaten Bulukumba yang telah ditetapkan Pemerintah Daerah sebagai destinasi wisata. Pulau Liukang Loe sangat unik dengan karakteristik budaya masyarakat lokal yang khas dan secara fisik wilayah pulau hampir dikelilingi pasir putih dan rataan terumbu karang yang tentu dapat mendukung kegiatan wisata bahari di Pulau Liukang Loe seperti aktivitas wisata pantai (rekreasi/bersantai). Kawasan pantai yang dibangun menjadi tempat wisata akan mengalami perubahan lingkungan baik secara nyata maupun tidak, terlebih apabila pembangunan kawasan pantai diikuti dengan beberapa aktivitas lain, seperti tempat pemukiman, pelelangan ikan, kuliner masakan laut, dan sekaligus menjadikan tempat rekreasi bagi wisatawan (Nawawi, 2013)

Tujuan penelitian ini adalah: 1) mengkaji kesesuaian kawasan untuk wisata pantai. 2) menganalisis daya dukung (carrying capacity) Pulau Liukang Loe untuk kegiatan wisata pantai.

\section{METODE PENELITIAN}

\section{Waktu dan Lokasi}

Penelitian ini dilaksanakan pada bulan Maret 2020 pengambilan data lapangan dan penelusuran data sekunder. Lokasi penelitian adalah Pulau Liukang Loe, Kabupaten Bulukumba, Provinsi Sulawesi Selatan.

\section{Jenis dan Sumber Data}

Penelitian ini dilakukan dengan metode survey dan studi literatur dimana data bersumber dari data primer yakni data yang dikumpulkan melalui observasi dan pengukuran langsung di lapangan dan data sekunder yang bersumber dari instansi terkait dengan pengelolaan Pulau Liukang Loe sebagai kawasan wisata 


\section{Penentuan Stasiun Penelitian}

Penentuan stasiun penelitian dilakukan berdasarkan keterwakilan variabilitas kondisi ekologi. Lokasi pengambilan contoh juga didasarkan pada keberadaan dan penyebaran sumberdaya biofisik yang bersumber dari data sekunder dan hasil survey lapangan. Data potensi sumberdaya penting yang diketahui dari data sekunder maka pengamatan hanya melakukan ground check. Pengukuran parameter biofisik perairan diukur dengan menggunakan pengukuran in situ.

Pengamatan data kondisi pantai untuk peruntukan wisata pantai meliputi parameter kemiringan pantai, tipe pantai, lebar pantai, penutupan lahan/vegetasi pantai, kedalaman perairan, substrat dasar perairan, kecepatan arus dan ketersediaan air tawar dilakukan dengan observasi dan pengukuran langsung di lapangan. Keberadaan pantai berpasir yang sesuai untuk wisata pantai berada di sebelah utara yaitu Kampung Ta'buntuleng, sebelah barat pulau dan sebelah tenggara pulau.

Tabel 1 Alat dan bahan yang digunakan.

\begin{tabular}{|c|c|c|}
\hline No & Alat dan Bahan & Fungsi \\
\hline 1 & GPS & Menentukan titik kordinat \\
\hline 2 & Roll Motor & Mengukur panjang pantai dan lebar pantai \\
\hline 3 & Kuisioner & Daftar pertanyaan \\
\hline 4 & Camera & Dokumentasi kegiatan \\
\hline 5 & Snorkling & Pengamatan biota berbahaya \\
\hline 6 & Current Meter & Untuk mengukur kecepatan arus \\
\hline 7 & Refraktometer & Mengukur salinitas \\
\hline 8 & Thermometer & Mengukur Suhu \\
\hline 9 & Seiche Disk & Mengukur kecerahan \\
\hline 10 & Sabak dan pensil & Alat tulis untuk mencatat \\
\hline
\end{tabular}

\section{Analisis Data}

Suatu kegiatan pemanfaatan yang akan dikembangkan hendaknya disesuaikan dengan potensi sumberdaya dan peruntukkannya. Matriks kesesuaian untuk ekowisata bahari meliputi peruntukkan untuk wisata pantai, wisata snorkling dan wisata selam (diving). Setiap kegiatan wisata mempunyai persyaratan sumberdaya dan lingkungan yang sesuai dengan objek wisata yang akan dikembangkan. 2010) :

Untuk menghitung kesesuaian wisata dapat menggunakan rumus (Yulianda et al.

Dimana :

$$
\mathrm{IKW}=\frac{N i}{N m a k s} \times 100 \%
$$

IKW = Indeks Kesesuaian Wisata

$\mathrm{Ni}=$ Nilai parameter ke-i (bobot $\mathrm{x}$ skor)

$\mathrm{N}_{\text {maks }}=$ Nilai maksimum dari suatu kategori wisata

Penentuan kesesuaian berdasarkan perkalian dari skor dan bobot yang diperoleh dari setiap parameter. Kesesuaian kawasan dilihat dari tingkat persentase kesesuaian yang diperoleh melalui penjumlahan nilai dari seluruh parameter.

Penentuan kesesuaian berdasarkan perkalian dari skor dan bobot yang diperoleh dari setiap parameter. Kesesuaian kawasan dilihat dari interval kesesuaian yang diperoleh dari penjumlahan nilai dari seluruh skor parameter yang dibandingkan 
dengan nilai maksimal dari setiap indeks kesesuaian dari setiap jenis aktivitas wisata. Persen interval yang didapatkan dari perhitungan indeks adalah sebagai berikut, kategori tidak sesuai (TS) yaitu $<37.5 \%$, sesuai bersyarat (SB) $37.5 \%-<62.5 \%$, sesuai (S) $62.5 \%-<87.5 \%$ dan sangat sesuai (SS) sebesar $87.5 \%-100 \%$.

Hasil analisis kesesuaian yang ada dari kawasan yang sangat sesuai dan sesuai akan digunakan sebagai dasar penentuan daya dukung sebagai luas atau panjang area yang dimanfaatkan (Lp). Daya dukung dihitung agar diketahui jumlah maksimum pengunjung yang secara fisik dapat ditampung di kawasan yang tersedia pada waktu tertentu tanpa menimbulkan gangguan pada alam dan manusia. Perhitungan Daya Dukung Kawasan (DDK) tersebut dapat dilihat dalam persamaan berikut (Yulianda et al. 2010) :

Dimana :

$$
\mathrm{DDK}=\mathrm{K} \times \mathrm{Lp} / \mathrm{Lt} \times \mathrm{Wt} / \mathrm{Wp}
$$

DDK = Daya Dukung Kawasan

$\mathrm{K} \quad$ = Potensi ekologis pengunjung per satuan unit area

Lp = Luas area atau panjang area yang dimanfaatkan

Lt $\quad=$ Unit area untuk kategori tertentu

Wt = Waktu yang disediakan kawasan untuk kegiatan wisata dalam 1 hari

$\mathrm{Wp}=$ Waktu yang dihabiskan oleh pengunjung untuk setiap kegiatan tertentu

\section{HASIL DAN PEMBAHASAN}

\section{Karakteristik Pantai}

Pulau Liukang Loe tidak semua dikelilingi oleh pantai berpasir. Pantai berpasir hanya ditemui disisi utara, selatan dan timur pulau dengan lebar pantai yang bervariasi. Lebar pantai sebelah utara pulau rata-rata $30 \mathrm{~m}$, sebelah tenggara $13 \mathrm{~m}$ dan sebelah barat $5 \mathrm{~m}$. Pantai Liukang Loe merupakan tipe pantai berpasir halus dengan tingkat kecerahan perairan mencapai $100 \%$ serta tingkat kemiringan pantai yang landai 3-10 . Penutupan lahan rata-rata vegetasi pantai di pulau ini terbagi beberapa bagian dimana vegetasi tergantung dari kondisi tekstur tanahnya. Untuk wilayah pemukiman (berpasir) umumnya vegetasi didominasi oleh tanaman kelapa, pisang, mangga, pepaya, dan tanaman perdu.

Hasil wawancara dengan penduduk lokal menunjukkan bahwa gelombang besar dari arah Barat terjadi pada bulan Januari-Maret (musim barat) yang menggerakkan sedimen ke arah timur dan sebaliknya pada musim Timur (Juli-Agustus) dimana gelombang datang dari arah tenggara membawa sedimen ke arah barat kembali sehingga terjadi keseimbangan kembali. Hal ini menunjukkan bahwa dinamika sedimen pantai sangat bergantung kondisi gelombang yang dibangkitkan oleh angin muson (musim barat dan timur).

Untuk biota berbahaya seperti bulu babi hanya ditemukan pada pantai sebelah selatan sementara pantai bagian utara dan barat hampir tidak ditemukan. Sedangkan sumber air tawar berada di sekitar pantai karena adanya pemukiman yang memiliki sumber air dari sumur. Tipologi pantai Pulau Liukang Loe yang seperti ini sangat sesuai untuk dimanfaatkan sebagai wisata rekreasi pantai. Hal ini terbukti dengan adanya kawasan pantai yang dimanfaatkan sebagai tempat wisata. 


\section{Analisis Kesesuaian Wisata Pantai}

Wisata pantai adalah jenis wisata yang memanfaatkan pantai dan perairan tepi pantai sebagai obyek dan daya tarik wisata dan kepentingan rekreasi. Pulau Liukang Loe memiliki panjang garis pantai $\pm 3 \mathrm{~km}$. Kawasan pantai Pulau Liukang Loe yang merupakan pantai berpasir dan tidak bervegetasi berdasarkan hasil pengamatan berada pada wilayah Utara dan Barat.

Salah satu daerah yang sesuai dan telah dijadikan untuk wisata pantai adalah pantai sebelah utara atau terletak di Kampung Ta'buntuleng (Gambar a dan b) karena dianggap memiliki panorama yang indah oleh wisatawan serta menjadi spot bagi wisatawan yang datang berlibur. Potensi ini juga dapat dijadikan sebagai alternatif bagi wisatawan sehingga tidak terfokus pada satu jenis wisata saja. Aktivitas wisata pantai yang bisa dilakukan disekitar wilayah pantai Liukang Loe mulai dari kegiatan berjemur, bersantai, melihat pemandangan, berkemah serta olahraga pantai.

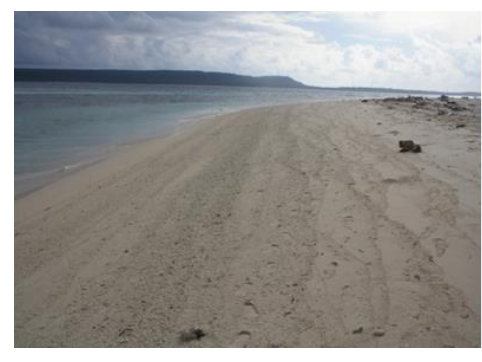

(a)

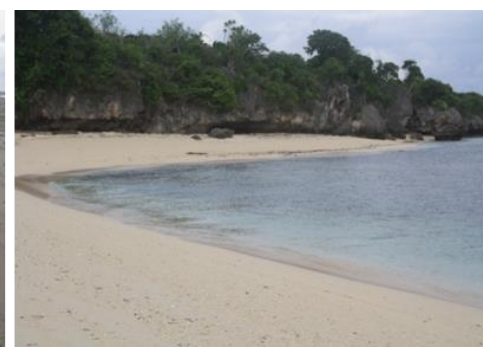

(b)

Gambar 1. Tipologi Pantai di Pulau Liukang Loe (Sumber : Dokumentasi Pribadi)

Hasil analisis menunjukkan dua kelas kesesuaian, yaitu sesuai (S) - warna hijau dengan panjang pantai $1411 \mathrm{~m}$ dan sesuai bersyarat (SB) - warna kuning dengan panjang pantai $1279 \mathrm{~m}$, sehingga total potensi untuk wisata pantai sekitar $2690 \mathrm{~m}$. Kelas sesuai berada di pantai sebelah utara (Kampung Ta'buntuleng) dengan potensi ekologis atau panjang area yang dimanfaatkan sebesar $932 \mathrm{~m}$, pantai sebelah barat dengan panjang area yang dimanfaatkan sebesar $164 \mathrm{~m}$ dan pantai sebelah tenggara (Kampung Pasilohe) dengan panjang area yang dimanfaatkan sebesar $318 \mathrm{~m}$. Adanya kategori kelas sesuai untuk wisata pantai didasarkan pada keberadaan panorama alam pantai pasir putih dan tingkat kecerahan perairan yang sangat jernih yang hampir terdapat pada kawasan pulaupulau kecil.

Sementara itu kelas sesuai bersyarat dikarenakan adanya penutupan lahan pantai oleh vegetasi belukar dan pohon kelapa, lebar pantai yang kecil, tipe pantai yang terjal, material dasar berlumpur dan berkarang serta keberadaan biota berbahaya seperti bulu babi meskipun jarak dengan pemukiman penduduk relatif dekat. Parameter fisik penentu kesesuaian ekowisata pantai menurut Daby (2003) terkait dengan keruhnya air dan keberadaan biota berbahaya di atas dan di dalam sedimen pada musim tertentu yang menunjukkan kualitas lingkungan di sekitar pantai yang buruk dan dapat mengancam keselamatan para turis.

\section{Analisis Daya Dukung Wisata Pantai}

Pantai berpasir putih dengan tipe susbtrat berpasir merupakan faktor utama yang berperan dalam penentuan pemanfaatan kawasan ekowisata untuk kegiatan wisata pantai sehingga diberikan bobot yang tinggi (3). Hal ini karena pantai berpasir putih memiliki 
daya tarik bagi wisatawan untuk melakukan aktivitas seperti berjemur, berenang, olahraga volley pantai ataupun hanya duduk-duduk sambil menikmati pemandangan alam. Hasil analisis kesesuaian menunjukkan bahwa ada 3 stasiun pengamatan yang termasuk kategori yang sesuai untuk kegiatan rekreasi pantai. Berdasarkan hasil analisis, maka diperoleh pada pantai sebelah utara atau stasiun Kampung Ta'buntuleng jumlah wisatawan yang dapat ditampung sebesar 37 orang/hari, pantai sebelah barat pulau dengan jumlah wisatawan yang dapat ditampung sebesar 6 orang/hari dan pantai sebelah tenggara pulau atau stasiun Kampung Pasilohe jumlah wisatawan yang dapat ditampung sebesar 13 orang/hari atau total panjang pantai yang sesuai untuk wisata pantai $1411 \mathrm{~m}$ dan jumlah wisatawan yang dapat ditampung untuk wisata pantai setiap hari adalah 56 orang/hari dengan waktu yang dibutuhkan setiap wisatawan untuk beraktivitas selama 3 jam. Hal ini menunjukan bahwa banyaknya wisatawan yang dapat melakukan aktivitas wisata di pantai sangat dipengaruhi oleh panjang pantai.

Tabel 1. Nilai daya dukung kawasan Wisata Pantai

\begin{tabular}{ccr}
\hline No & Potensi Ekologis Pantai (Lp) & DDK (Orang/Hari) \\
\hline 1 & $1411 \mathrm{~m}$ & 56 \\
\hline & Total & 56 orang/hari \\
\hline & & 20440 orang/tahun \\
\hline
\end{tabular}

\section{KESIMPULAN DAN SARAN Kesimpulan}

Berdasarkan hasil analisis Indeks Kesesuaian Wisata (IKW), Pulau Liukang Loe kategori wisata pantai termasuk dalam kategori sesuai dengan panjang pantai $1.411 \mathrm{~m}$ dan sesuai bersyarat dengan panjang pantai $1.279 \mathrm{~m}$. Kategori sesuai berada di pantai sebelah utara (Kampung Ta'buntuleng) dan kategori sesuai bersyarat berada di pantai sebelah tenggara (Kampung Pasilohe) dengan daya dukung kawasan kategori wisata pantai sebesar 56 (Orang/hari).

\section{Saran}

Perlu adanya kerja sama antar stakeholder dalam upaya mempromosikan kawasan wisata pantai di Pulau Liukang Loe sehingga kunjungan mengalami peningkatan dengan tetap memperhatikan kesesuaian dan daya dukung yang ada agar pemanfaatan optimum dan lestari.

\section{UCAPAN TERIMA KASIH}

Ucapan terima kasih kami ucapkan kepada seluruh masyarakat Pulau Liukang Loe yang menerima kami dengan baik untuk melakukan penelitian ini. Tak lupa juga kami haturkan ucapan terima kasih kepada Dinas Kelautan dan Perikanan Kabupaten Bulukumba, Dinas Kebudayaan dan Pariwisata Kab. Bulukumba dan Camat Bontobahari atas bantuan untuk memberikan izin melakukan penelitian dan menyediakan data-data pendukung penelitian. 


\section{DAFTAR PUSTAKA}

Ali, D (2004). Pemanfaatan Potensi Sumberdaya Pantai Sebagai Obyek Wisata Dan Tingkat Kesejahteraan Masyarakat Sekitar LokasiWisata (Studi Kasus Di Kawasan Wisata Pantai Kartini Jepara). Program Pascasarjana Universitas Diponegoro. Semarang

Bengen, DG (2003). Definisi, Batasan dan Realitas Pulau-pulau Kecil. Makalah disajikan pada Seminar Sehari Validasi Jumlah Pulau-pulau dan Panjang Garis Pantai di Indonesia.

Dahuri, R (2003). Keanekaragaman hayati laut aset pembangunan berkelanjutan Indonesia. PT Gramedia Pustaka Utama.

Nawawi, Ahmad (2013). Partisipasi Masyarakat dalam Pengelolaan Wisata Pantai Depok di Desa Kretek Parangtritis. Jurnal Nasional Pariwisata.

Yulianda, Fredinan, et al. (2010). Pengelolaan Pesisir dan Laut Secara Terpadu. Book 3. Bogor (ID): Pusdiklat Kehutanan-Departemen Kehutanan RI-SECEM- Korea International Coorporation Agency. 